\title{
KILKA UWAG NA MARGINESIE BADAŃ STOSUNKÓW SPOŁECZNYCH LUDNOŚCI „,UUŻYCKIEJ”
}

\author{
SOME REMARKS ON THE MARGIN OF STUDIES ON SOCIAL \\ RELATIONS OF 'LUSATIAN' CULTURE COMMUNITIES
}

\begin{abstract}
The presented paper aims at addressing one of aspects of study of social relations in the Lusatian culture, namely exclusion of some children bodies from the kin cemetery. In the course of the Lusatian culture development, this self-inclusiveness of human groups ceased leading to attributing the kin status even to the newborns. However, recent studies of numerous Lusatian cemeteries seem to question this hypothesis. This discrepancy can be partly explained by burying some infants, as well as adults, in consecrated places outside the kin cemeteries. This is well manifested in case of the settlement at Łęczyska, Łódź province where dozens of children and adults have been buried in distinctively isolated three zones, which correspond to the triple model of the rite de passage. This clearly implies that even individuals, otherwise excluded from a given social group, are treated with due honor and respected after the death so their souls can be granted eternal peace.
\end{abstract}

Truizmem jest stwierdzenie, że problematyka pradziejowych stosunków społecznych jest bardzo złożona. Należy mieć jednak świadomość, że ustalenia badaczy dotyczące tych stosunków, a raczej ich organizacji, tj. struktury społecznej, bazujące tak na faktach bezpośrednich, w szczególności na cmentarzyskach czy rozmiarach i strukturze obozowisk oraz pośrednich, do których należą m.in. stosunki gospodarcze i tryb życia określonych społeczeństw, są w pewnym stopniu zeschematyzowane. Wpływ na taki stan rzeczy ma niewątpliwie przyjmowanie a priori założenia, wynikającego z materializmu historycznego, że rozwój społeczny także w pradziejach przebiegał w ten sposób, że określone społeczeństwa musiały przechodzić przez pewne określone etapy rozwojowe, o charakterze standardowym i uniwersalnym, co powodowało w ostateczności, że etap „wyższy” następował po „niższym”.

W archeologii zamyka się etap myślenia pozytywistycznego, gdzie źródło archeologiczne stawało się nie środkiem, ale celem samym w sobie, ograniczając badania do faktografii, z pominięciem wiedzy teoretycznej, co podkreślał już J. Topolski . Obecnie coraz częściej dostrzega się konieczność pełniejszego spojrzenia na przedmiot badań archeologicznych, analizę struktury rzeczywistości dziejowej, której dotyczą formuło-

\footnotetext{
${ }^{1}$ Ostoja-Zagórski 1996, s. 68.

${ }^{2}$ Topolski 1983, s. 155.
} 
wane przez archeologa twierdzenia, a więc społeczeństwo i kulturę ${ }^{3}$. Wnosi się postulat połączenia dwóch płaszczyzn: archeologii $\mathrm{i}$ etnologii w interpretacjach społecznych i symbolicznych ${ }^{4}$, zwłaszcza że archeologia nadal szczególnie chętnie bada rytuały ofiar z ludzi i zwierząt w aspekcie układów przestrzennych ${ }^{5}$.

Przyjrzyjmy się zatem temu zagadnieniu. Materiały grobowe są głównym źródłem orzekania o zróżnicowaniu społecznym, przy czym zazwyczaj przyjmuje się pozytywny związek wyposażania grobów i niezbędnej sumy energii wydatkowanej na przygotowanie grobu ze statusem osoby w nim pochowanej ${ }^{6}$, choć zwraca się także uwagę na niebezpieczeństwo dosłownego utożsamiania form grobów i ich wyposażenia z pozycją społeczną pochowanych w nich osób ${ }^{7}$. Mając na uwadze te fakty, przyjrzyjmy się grobom dziecięcym.

Spotyka się je stosunkowo często na osadach z okresu neolitu ${ }^{8}$, natomiast są raczej rzadkością na osadach ludności kultury łużyckiej ${ }^{9}$. Sytuacja taka została zarejestrowana m.in. w Małopolsce, na stanowisku w miejscowości Janowice, woj. małopolskie, datowanym na przełom $\mathrm{V}$ okresu epoki brązu i okresu halsztackiego $\mathrm{C}^{10}$, jednakże były to badania o charakterze sondażowym, stąd określenie relacji cmentarzysko-osada jest wyjątkowo trudne. Walory porównawcze przekreśla ponadto brak analiz antropologicznych. W okolicy Kalisza, w miejscowości Wieruszów, woj. łódzkie, na grodzisku ludności kultury łużyckiej z przełomu okresu halsztackiego C i D, został odkryty ciałopalny grób dziecka ${ }^{11}$. Oprócz lakonicznej informacji o jego lokalizacji (,pomiędzy paleniskami a właściwym wałem”), brak niestety dalszych danych, m.in. szczegółowej analizy antropologicznej. Wymieniona autorka podaje w wątpliwość intencjonalność bruku kamiennego (stropowego?), mimo że bruki takie spotykane są nad grobami na cmentarzysku związanym z grodziskiem. Pojedyncze ciałopalne groby zostały także odkryte na halsztackich grodziskach ludności kultury łużyckiej w Grodnie w okolicach Chełmży, woj. kujawsko-pomorskie ${ }^{12}$ i Gzinie, woj. kujawsko-pomorskie ${ }^{13}$. W przypadku grodu w Grodnie jest to pojedynczy grób dziecka, natomiast w Gzinie ciałopalne groby, prawdopodobnie dzieci, zostały odkryte na dnie „studniowatych” jam i interpretuje się je jako ofiary z ludzi, wiązane z praktykami kanibalistycznymi ${ }^{14}$, stąd nie mogą mieć one walo-

\footnotetext{
${ }^{3}$ Pałubicka, Tabaczyński 1986.

${ }^{4}$ Minta-Tworzowska 2000, s. 51.

${ }^{5}$ Minta-Tworzowska 2000, s. 49.

${ }^{6}$ Brenan 1985, s. 126-129; Jorgensen 1988, s. 17, 18; Mü11er 1994a; 1984b.

${ }^{7}$ Hodder 1995, s. 158 n.

${ }^{8}$ Pyzel, Sobkowiak-Tabaka 2004.

${ }^{9}$ Informacja ustna dr. Jerzego Kozaka, za którą autorka serdecznie dziękuje.

${ }^{10}$ Prokopowicz 1961.

${ }^{11}$ Jadczykowa 1986

${ }^{12}$ Gackowski 2003.

${ }^{13}$ Chudziakowa 1992.

${ }^{14}$ Chudziakowa 1992, s. 18 n.
} 
ru porównawczego. Niespalone szczątki ludzkie, głównie osobników młodocianych, zostały odkryte na grodzisku z okresu halsztackiego D w Słupcy, woj. wielkopolskie ${ }^{15}$, jednakże kości były porozrzucane bezładnie i nosiły ślady osmalenia ogniem, co przemawia raczej za gwałtowną śmiercią w wyniku najazdu na gród ${ }^{16}$. Wypada też wspomnieć o pojedynczym grobie dziecka na osadzie w Zabrzeziu, woj. łódzkie ${ }^{17}$.

Problematyka pochówków dziecięcych jest rzadko poruszana w literaturze przedmiotu, stąd ważne są spostrzeżenia J. Dąbrowskiego ${ }^{18}$ odnośnie do zmian procentowego udziału pochówków dziecięcych na cmentarzyskach pradziejowych. Autor ten zwraca uwagę, że w epoce brązu następuje pewien znaczący przełom w traktowaniu zmarłych dzieci i o ile wcześniej niewątpliwie znaczna ich część nie była grzebana na wspólnych cmentarzyskach, o tyle $\mathrm{w}$ epoce brązu odsetek zwłok dzieci niedopuszczanych na wspólne miejsce pochówku staje się niewielki. Ten stan rzeczy tłumaczy on znacznym zmniejszeniem się ekskluzywności grup społecznych w czasach trwania w Europie Środkowej kultury łużyckiej, będącej wynikiem przełamania izolacji sąsiedzkiej wskutek istnienia stałych, powtarzalnych (a więc unormowanych) kontaktów różnych grup ludzkich spowodowanych potrzebą uzyskiwania surowca i przedmiotów brązowych. Musiało to rzutować na całokształt stosunków społecznych w tym czasie i doprowadziło w ostateczności do traktowania obcych jednostek i grup ludzkich już nie jako wrogów, ale partnerów w interesach. Konsekwencją takiego stanu rzeczy jest ułatwienie przyjęcia członkostwa grupy ludzkiej nadawanego już niemowlakom, traktowanie obrzędu inicjacji tylko w aspekcie symbolicznym i tym samym zmniejszona rola predestynacji społecznej nie tylko odnośnie do osobników związanych z daną grupą społeczną więzami krwi, ale także i obcych. Równocześnie autor zwraca uwagę, że dane uzyskane z różnych cmentarzysk są o wiele niższe od oczekiwanych, co świadczyłoby, że nadal nie wszystkie zmarłe dzieci chowano na wspólnym cmentarzysku, słusznie zakładając w miarę przyrostu materiałów napływ nowych informacji źródłowych.

Prowadzone w ostatnich latach szerokopłaszczyznowe badania ratownicze, nie tylko na cmentarzyskach, ale i osadach rzucają nowe światło na to zagadnienie. W szczególności uwagę zwraca osada w Łęczyskach, woj. łódzkie ${ }^{19}$, na której oprócz obiektów typowo osadniczych, zarejestrowano skupiska grobów, a puste przestrzenie wokół nich sugerują świadomy wybór miejsca grzebania zmarłych. Na osadzie tej odkryto łącznie 29 grobów ciałopalnych, a analiza antropologiczna wykazała obecność szczątków 29 osobników: 9 noworodków, 15 osobników w wieku infans, 1 osobnik w wieku infans IIljuvenis, $1 \mathrm{w}$ wieku juvenis/adultus, $2 \mathrm{w}$ wieku adultus oraz 1 nieokreślonego wieku. Poza 7 przypadkami groby wystąpiły w trzech wyraźnych skupiskach: wschodnim, północ-




nym oraz zachodnim. Zauważalna jest także pewna prawidłowość: w skupisku wschodnim pochowano głównie noworodki, a w północnym i zachodnim przede wszystkim osobniki w wieku infans. Każdemu skupisku grobów dzieci towarzyszył pochówek osoby lub osób starszych. Poza wyróżnionymi skupiskami, w północnej części stanowiska dominują groby noworodków, natomiast w części południowej osób w wieku infans II.

W przypadku grobów $\mathrm{z}$ osady w Łęczyskach mamy niewątpliwie do czynienia z niedopuszczeniem niektórych dzieci oraz osób dorosłych na wspólne cmentarzysko. Przyczyn niedopuszczenia dzieci może być wiele. Odmowa pochowania na wspólnym cmentarzysku osobników dorosłych z jednej strony mogła dotyczyć osób pochodzących $\mathrm{z}$ danej zbiorowości, ale pozostających poza jej nawiasem z przyczyn, których nie jesteśmy w stanie dziś odczytać. Z drugiej strony takie odrębne traktowanie danej osoby może być dowodem, iż pochodziła ona z zewnątrz, w sensie z innej zbiorowości ludzkiej, nie nabywając praw społeczeństwa, w którym się znalazła ${ }^{20}$. W przypadku dzieci odmowa pochowania na wspólnym cmentarzysku mogła spotkać osobniki upośledzone umysłowo czy fizycznie bądź wcześniaki, jak również nieuznane przez ojca, rzadziej matkę, a więc nieprzyjęte formalnie do rodziny ${ }^{21}$ i tym najczęściej tłumaczy się zaobserwowany fakt wykluczania dzieci i/lub osobników młodocianych poza nawias społeczeństwa $^{22}$. Powszechność obrzędu inicjacji, występującego w najróżniejszych formach, m.in. uznanie za członka rodziny, pozwala przypuszczać, że nie był on obcy i ludności kultury łużyckiej, tym bardziej że znany był u Celtów, Germanów czy Rzymian ${ }^{23}$, jak i w średniowieczu (np. postrzyżyny Ziemowita). Właśnie dla okresu średniowiecza mamy zdecydowanie najwięcej danych o rytuałach pogrzebowych dotyczących dzieci. Wraz z ideologią chrześcijańską przyjęto rytuał pogrzebowy zalecany przez Kościół, w myśl którego mogły być pochowane tylko dzieci ochrzczone jako członkowie wspólnoty religijnej. Tym, które zmarły przed otrzymaniem sakramentu chrztu, nie przysługiwał pochówek w poświęconej ziemi - grzebano je w chlewie, na polu, na rozstajach dróg, w pobliżu krzyża przydrożnego ${ }^{24}$, pod murami cmentarzy, a nawet w dzwonnicach ${ }^{25}$. Natomiast dzieci ochrzczone ,,z wody” przez szafarza świeckiego (np. matkę lub ojca) mogły być pochowane zgodnie z rytuałem kościelnym. Dzieciom nieochrzczonym w eschatologii chrześcijańskiej nie poświęcano wiele miejsca. Przedwczesna lub nienaturalna śmierć zawsze budziła lęk, ponieważ zaprzeczała logice bytu ludzkiego, filozofii życia jako takiego. Zakłócało to porządek rzeczy, łączyło się z niedopełnieniem losu ludzkiego i zatem było czymś nienaturalnym, co stwarza zagrożenie powrotu zmarłego do grona żywych. Jeśli przyjąć, że śmierć stanowiła przejście z jednego stanu do drugiego, to owo przejście wymagało dopełnienia obowiązującym rytuałem pogrzebowym,

\footnotetext{
${ }^{20}$ Rysiewska 1996.

${ }^{21}$ Häusler 1968, s. 6 n.

${ }^{22}$ Wiślański 1969, s. 309.

${ }^{23}$ Kietlińska 1959, s. 103 n.; Przeworska 1971, s. 52.

${ }^{24}$ Delimata 2004, s. 100.

${ }^{25}$ Kowalczyk 2004, s. 106.
} 
który zamykał czas pobytu zmarłego w świecie żywych i ułatwiał przejście do świata zmarłych, uniemożliwając jednocześnie jego powrót. Zaniechanie takich rytuałów (z różnych powodów) powodowało pozostawienie zmarłego w stanie pośrednim - zawieszenie go na granicy świata żywych i zmarłych ${ }^{26}$. Jeśli uświadomimy sobie, że zmarły człowiek jest w mitach obiektem czci religijnej lub obdarza się go ambiwalentną dla żyjących mocą, to cmentarzyska, czy raczej ich przestrzeń rozumie się nie tylko jako obszar nasycony sakralną mocą, ale też jako kategorię społeczną, kreowaną na poziomie ponadjednostkowym $^{27}$.

Cmentarzyska są jednym z wyróżniających się elementów, zwiększających w ludziach poczucie tożsamości, budzące świadomość i lojalność wobec miejsca - są wyznacznikiem ,ziemi rodzinnej” każdego ludu, a identyfikacja urodzonego tu człowieka nie budzi żadnych wątpliwości. Na przestrzeni pradziejów, od wczesnej epoki brązu aż po wczesną epokę żelaza cmentarzyska są wyraźnie rozgraniczane od części osadni$\mathrm{czej}^{28}$, a rozplanowanie grobów dowodzi przemyślanej decyzji o wyborze miejsca pod nie. Obraz przestrzeni grzebalnej ma właściwości zbliżone do trójdzielnego wzoru obrzędów przejścia: etapowi pierwszemu - separacji odpowiada na cmentarzyskach strefa południowo-wschodnia, etapowi trzeciemu - agregacji (ponownego umacniania wspólnoty żywych i przywracania jej uczestników rytuału) odpowiada strefa północno-zachodnia, a pomiędzy strefą separacji ze świata żywych i miejscem, gdzie odbywa się ponowna agregacja w jego zakres znajduje się obszar wypełniony pochówkami, region szczególnego nasilenia sacrum, poza rzeczywistym czasem i przestrzenią ${ }^{29}$.

Zamiar złożenia pochówku do wnętrza uświęconej powierzchni wiązał się z koniecznością wkroczenia do środka kręgu wytyczonego kamieniami, rowem lub paleniskami. Musiały istnieć zatem określone otwory komunikacyjne, tak w ramach cmentarzyska, jak i pojedynczych grobów, które umożliwiałyby przekraczanie granicy między światem żywych i światem umarłych, odpowiadające trójstopniowym schematowi rytuałów przejścia. Na wczesnobrązowych cmentarzyskach kultury unietyckiej odnotowano przykłady przerw w pierścieniu wału od strony południowej, na cmentarzyskach „łużyckich" domniemane wejścia do wnętrza obiektów sepulkralnych, tak w przypadku otaczania pochówków skrzyniami, jak i pierścieniem ułożonym z kamieni, także zarysowały się od strony południowej i południowo-wschodniej. Wyraźna waloryzacja określonych stref południowych i wschodnich w przekraczaniu granicy przestrzeni grobowej występuje także w przypadku późniejszych obiektów rowkowych z okresu przedrzymskiego i wczesnorzymskiego. Fenomen mitycznego południa i wschodu łączono w symbolice indoeuropejskiej z zasadą pozytywną - męską (redundantną), np. wobec symbolizmu ognia i słońca. Wejście w sakralny obszar od strony południowo-wschodniej

\footnotetext{
${ }^{26}$ Kowalczyk 2004, s. 105 n.

${ }^{27}$ Woźny 2000, s. 93.

${ }^{28}$ Woźny 2000, s. 111.

${ }^{29}$ Woźny 2000, s. 126.
} 
pozostawało równoznaczne $\mathrm{z}$ ruchem wstępującym, prowadzącym $\mathrm{w}$ górę, dlatego też cmentarzysko jak każdy obiekt uświęcony wymagało nie tylko rozgraniczenia, ale także wyniesienia ponad okoliczne terytoria. Wkraczanie w obręb nekropolii z zewnątrz odpowiadało równocześnie drodze $\mathrm{z}$ niżej położonych peryferii do sakralnego centrum wypełnionego pochówkami. Symbolika uświęconego środka jest powszechna w myśli religijnej i występuje uniwersalnie. Dostęp do „centrum” jest równoważny z konsekracją oraz inicjacją i odpowiada swą rangą najistotniejszemu rytuałowi przejścia. Zarówno poszczególne groby, jak i całe cmentarzyska, stają się poprzez uświęcone wytyczanie granic miejscami, w których manifestuje się idea dochodzenia do sakralnego środka ${ }^{30}$.

Odkryte na osadzie w Łęczyskach groby są wyraźnie oddzielone pustymi przestrzeniami od strefy mieszkalnej i gospodarczej, a ponadto występują w trzech skupieniach: wschodnim, północnym i zachodnim, co odpowiada trójdzielnemu schematowi obrzędów przejścia. Na stanowisku tym odkryto ponadto 2 obiekty rowkowe: jeden kształtu półksiężycowatego i drugi w kształcie odwróconej litery U. W pierwszym z nich „,wejście" skierowane było na północny wschód, natomiast w drugim na południowy wschód. Brakuje analogii z innych stanowisk kultury łużyckiej, nie można jednak wykluczyć ich powiązań z odkrytymi na stanowisku grobami: oba obiekty zlokalizowane były w odległości około $10 \mathrm{~m}$ od skupisk grobów, a ich „wejścia” skierowane były właśnie na owe skupiska pochówków. Podobne w kształcie obiekty rowkowe, których funkcję określa się jako kultową, zostały odkryte na cmentarzysku w Kietrzu, woj. opolskie i chociaż wiązane są mimo braku precyzyjnie datujących materiałów z kulturą lateńską, nie można wykluczyć, że mogły być wykorzystywane wcześniej, zważywszy, iż cmentarzysko to było użytkowane od schyłku II okresu epoki brązu, poprzez okresy halsztackie C i D, aż po starszy okres przedrzymski i rzymski ${ }^{31}$. Dodać jeszcze należy, że w stropie niektórych grobów zarejestrowano pojedyncze, lub kilka, kamienie wyznaczające najprawdopodobniej granice grobów. W przypadku dwóch grobów ściany południowe w profilu były proste, co sugeruje istnienie trudnego do określenia wzmocnienia $\mathrm{z}$ materiału organicznego. Symbolizuje to otwartość grobów od strony południowej.

W przypadku grobów z Łęczysk mamy do czynienia z niedopuszczeniem niektórych zmarłych na wspólne dla danej społeczności miejsce pochówku, co nie oznacza jednak, że odmówiono im w ogóle prawa do pochówku. Co więcej, obserwowana jest niezwykła wręcz dbałość o zaakcentowanie wyjątkowości miejsca ich pochówku, wyrażająca się ścisłą łącznością ze sferą sakralną poprzez nawiązanie do społecznie obowiązujących reguł „cmentarzyskowych”. Pozostaje natomiast otwarte pytanie o powód odmówienia tym osobnikom prawa do pochówku na wspólnym cmentarzysku. Wspomniałam na początku, że przyczyn takiego niedopuszczenia może być wiele, a jedną z nich jest m.in. brak akceptacji ze strony matki lub ojca lub nieotrzymanie pełnoprawnego członkostwa danej grupy społecznej w wyniku niedostąpienia aktu inicjacji. Hipoteza ta byłaby praw-

\footnotetext{
${ }^{30}$ Woźny 2000 , s. $127-133$.

${ }^{31}$ Gedl 1972, s. 114 n.
} 
dopodobna, gdyby szło wyłącznie o groby dziecięce. Musimy mieć jednak świadomość, że w każdym skupisku grobów dziecięcych wystąpiły pochówki osób dorosłych w świetle badań antropologicznych średnia wieku w kulturze łużyckiej w epoce brązu i wczesnej epoce żelaza wynosiła około $30-35$ lat $^{32}$, rzadko mniej ${ }^{33}$ lub więcej ${ }^{34}$, podobnie zresztą w kulturze pomorskiej ${ }^{35}$, stąd osobniki ze skupiska wschodniego określone na przedział wiekowy juvenis/adultus czy z północnego odnoszone do wieku infans IIIjuvenis można $\mathrm{z}$ dużą dozą prawdopodobieństwa uznać za osoby dojrzałe, które przeszły już etap inicjacji włączającej je do danej grupy społecznej, choć należy podkreślić, że pełny obraz zakłóca niestety niemożność określenia płci osób dorosłych. W literaturze przedmiotu wspólne pochówki dzieci zmarłych w wieku infans I oraz kobiet interpretuje się jako miejsce spoczynku matek i dzieci, których przyczyną śmierci były komplikacje okołoporodowe. Uważa się, że w przypadku śmierci matki zabijano także niemowlę, niezdolne do samodzielnego rozwoju ${ }^{36}$. Nie można więc wykluczyć, że były to osoby pochodzące $\mathrm{z}$ danej zbiorowości, ale pozostające poza jej nawiasem ${ }^{37} . \mathrm{Z}$ drugiej strony, w świetle ustaleń T. Rysiewskiej ${ }^{38}$ grupy społeczne kultury łużyckiej z epoki brązu i wczesnej epoki żelaza charakteryzowały się patrylinearną sukcesją pokrewieństwa, patrylokalną rezydencją małżonków, małżeństwem matrylateralnym i praktykowały uogólnioną wymianę małżeńską, czego wyrazem jest mniej staranne konstruowanie i mniej zasobne wyposażanie grobów zarówno mężczyzn przyżenionych do grupy, jak i kobiet pochodzących spoza społeczności. Osobniki dorosłe pochowane w wymienionych wyżej skupiskach można więc uznać za przedstawicieli innej grupy społecznej, a nie można wykluczyć, że i o innym typie kultury, jeśli uwzględni się możliwość wymiany małżeńskiej pomiędzy społecznością ,łużycką” a „pomorską". Na obszarze środkowej Polski, a zwłaszcza na terenie Bełchatowa, woj. łódzkie tak mogło być, czego dowodem jest rozległy kompleks osadniczy z okresów halsztackiego i lateńskiego w Grabku, woj. łódzkie, użytkowany bez przerw zarówno przez ludność „łużycką”, jak i ,pomorską, ${ }^{39}$. Zastanawiająca niewielka liczba pochówków na związanym z tym kompleksem osadniczym cmentarzysku, określanym jako miejsce pochówku jednych z pierwszych tutaj przedstawicieli ludności kultury pomorskiej ${ }^{40}$, może być tłumaczona

${ }^{32}$ Szybowicz 1996, s. 486; Rożnowski 1989, s. 150; Strzałko, Olińska 1983, s. 454, tab. 1.

${ }^{33}$ Bugajska, Gedl 1983, s. 463.

${ }^{34}$ Piontek 1983, s. 461, 462, tab. 3, 4.

${ }^{35}$ Rożnowski 1993, s. 323.

${ }^{36}$ Malinowski 1985 , s. 369.

${ }^{37}$ Aż do schyłku XV w. brak informacji o karach jakie spotykały matki za spędzenie płodu. Dopiero później mówi się o ograniczeniu kompetencji kasztelańskiej w stosunku do takich kobiet (Kowalczyk 2004, s. 107). Nie można zatem wykluczyć, że w przypadku śmierci takiej kobiety odmawiano jej prawa do pochówku na wspólnym cmentarzysku.

${ }^{38}$ Rysiewska 1996, s. 247.

${ }^{39}$ Muzolf 2002, s. 121-378.

${ }^{40}$ Urbański 2002, s. 399. 
jako wynik owej lokalnej wymiany małżeńskiej, tym bardziej że osada w Łęczyskach jest z nim zsynchronizowana czasowo. $Z$ całą pewnością dowodem na istnienie wymiany międzygrupowej i pokojowej współegzystencji różnych grup ludzkich w ramach jednej osady jest stanowisko $\mathrm{nr} 12 \mathrm{w}$ Chabielicach, woj. łódzkie ${ }^{41}$. Brakuje określeń płci dzieci, niedającej się uchwycić, ale jeśli uznać założoną przez T. Rysiewską patrylinearność, to groby dziecięce występujące $\mathrm{w}$ tych skupiskach byłyby pochówkami dzieci należącymi do innej grupy społecznej. W przypadku 7 grobów dziecięcych występujących na omawianej osadzie poza wyróżnionymi skupiskami, można przypuszczać, że są to pochówki dzieci pochodzących z tej zbiorowości, które nie zostały do niej przyjęte z powodów wymienionych wyżej. Nie oznacza to, że odmówiono im prawa do pochówku - niemal wszystkie z nich zostały złożone do popielnicy, a pochówek jednego niemowlęcia (gr. 64) był ponadto wyposażony w liczne przystawki czy prawa do rytuału pogrzebowego (w pobliżu tego grobu została bowiem odkryta gliniana grzechotka). W literaturze przedmiotu istnieje rozbieżność opinii odnośnie do funkcji grzechotek rozumianych albo jako dziecięce zabawki ${ }^{42}$, albo jako przedmioty pełniące trudne do określenia role w obrzędowości związanej z kultem solarnym bądź lunarnym ${ }^{43}$, choć wydaje się, iż rację mają ci autorzy, którzy sugerują ich funkcję związaną z obrzędami, w których „,bohaterami" były małe dzieci ${ }^{44}$.

Jakkolwiek słuszne jest stwierdzenie, że nie wszystkie dzieci chowane były na wspólnym cmentarzysku ${ }^{45}$, takie tłumaczenie tego faktu chociażby w kategoriach kanibalizmu (w literaturze przedmiotu zwracano uwagę na fakt częstego występowania szczątków dziecięcych wśród znalezisk kości ludzkich o charakterze pozostałości kanibalizmu lub ofiar ${ }^{46}$ ) budzi dziś poważne zastrzeżenia. Przykład osady w Łęczyskach dowodzi, że te z dzieci, które nie zostały pochowane na wspólnym cmentarzysku, także otaczane były czcią po śmierci. Być może za ich pośrednictwem możliwe stawało się nawiązanie duchowego kontaktu ze zmarłymi przodkami, w celu uzyskania ich przychylności ${ }^{47}$. Pozostaje mieć nadzieję, że kolejne badania potwierdzą tę hipotezę.

\section{BIBLIOGRAFIA}

Wykaz skrótów

Badania - Badania archeologiczne na terenie odkrywki „Szczerców” Kopalni Węgla Brunatnego „Bełchatów”

\footnotetext{
${ }^{41}$ Frąsiak, Gwóźdź, Siciński 2000, s. 51.

${ }^{42}$ Ćwirko-Godycki, Wrzosek 1936-1937, s. 248; Wieczorowski 1938, s. 37.

${ }^{43}$ Gediga 1979, s. 335; Jażdżewski 1981, s. 338; Ged1 1989, s. 689.

${ }^{44} \mathrm{Jadczyk}$ owa 1996, s. 233.

${ }^{45}$ Dąbrowski 1973, s. 348.

${ }^{46}$ Häusler 1966, s. 64; Malinowski 1968.

${ }^{47}$ Jung 1988.
} 


\section{Literatura}

Anioła M., Głogowski Z., Kiona-Podhajny M., Panczenko M.

2003 Osadnictwo ludności kultury łużyckiej i pomorskiej, (w:) Badania, t. 4, red. M. Chłodnicki, Poznań, s. $37-129$.

Brenan J.

1985 Assessing Social Status in the Anglo-Saxon Cementery ta Sleaford, „Bulletin of the Institute of Archaeology" 21/22, s. 125-131.

Bugajska B., Gedl M.

1983 Badania zespołu osadniczego ludności grupy tarnobrzeskiej w Bachórzu-Chodorówce, (w:) Przemiany ludnościowe i kulturowe I tysiąclecia p.n.e. na ziemiach między Odrą a Dnieprem, red. W. Hensel, Wrocław, s. 463-465.

Ćwirko-Godycki M., Wrzosek A.

1936-37 Grzechotki z grobów cmentarzyska hużyckiego w Laskach w pow. kępińskim, „Światowit” 17, s. 171-254.

Chudziakowa J.

1992 Grodzisko kultury łużyckiej w Gzinie, Toruń.

Dąbrowski J.

1973 Z problematyki stosunków społecznych ludności kultury łużyckiej, „Archeologia Polski”, t. XVIII, z. 2, s. 337-351.

Delimata $\mathrm{M}$.

2004 Rytual pogrzebowy dzieci w Polsce średniowiecznej i wczesnonowożytnej, (w:) Dusza maluczka a strata ogromna, Funeralia Lednickie (Spotkanie 6), red. W. Dzieduszycki, J. Wrzesiński, Poznań, s. 99-103.

Frąsiak P., Gwóźdź B., Siciński W.

2000 Wyniki ratowniczych badań archeologicznych na terenie odkrywki „Szczerców” $K W B$ „Bełchatów” SA na stan. 12 w miejscowości Chabielice, gm. Szczerców, woj. łódzkie, (w:) Badania, t. 1, red. R. Grygiel, Łódź, s. 25-188.

Gackowski J

2003 Uwagi o niektórych materiałach zabytkowych z osiedla obronnego kultury hużyckiej w Grodnie koło Chełmży (na podstawie wyników badań z lat 1997-2001), (w:) XIII Sesja Pomorzoznawcza, t. 1, red. M. Fudziński, H. Paner, Gdańsk, s. 105-115.

Gediga B

1979 Zagadnienia religii, (w:) Prahistoria ziem polskich, t. IV: Od środkowej epoki brązu do środkowego okresu lateńskiego, red. J. Dąbrowski, Z. Rajewski, Wrocław, s. 320-342.

Gedl M.

1975 Kultura hużycka, Kraków.

1989 Stosunki społeczne. Wierzenia i praktyki kultowe, (w:) Pradzieje ziem polskich, t. I: Od paleolitu do środkowego okresu lateńskiego, cz. 2: Epoka brązu i początek epoki żelaza, red. J. Kmieciński, Warszawa-Łódź, s. 689-692.

Häusler A.

1966 Zum Verhältnis von Männern, Frauen und Kinder in Gräbern der Steinzeit, „Arbeits- und Forschungsberichte zur sächsischen Bodendenkmalpflege", t. 14/15.

1968 Kritische Bemerkungen zum Versuch soziologischer Deutungen ur- und frühgeschichtlichen Gräberfelder erläutert am Beispiel des Gräberfeldes von Hallstatt, „Ethnographisch-Archäologische Zeitschrift", t. 9.

Hodder I.

1995 Czytanie przeszłości. Współczesne podejścia do interpretacji w archeologii, Poznań. 
Jadczykowa I.

1986 Grodzisko kultury hużyckiej w Wieruszowie-Podzamczu, województwo kaliskie. Badania 1973-1977, „Prace i Materiały Muzeum Archeologicznego i Etnograficznego w Łodzi”, seria archeologiczna nr 30, s. 267-291.

1996 Gliniane grzechotki kultury hużyckiej w zbiorach Muzeum Archeologicznego i Etnograficznego w Lodzi, (w:) Problemy epoki brązu $i$ wczesnej epoki żelaza w Europie środkowej. Księga jubileuszowa poświęcona Markowi Gedlowi, red. J. Chochorowski, Kraków, s. 227-237.

Jażdżewski K.

1981 Pradzieje Europy Środkowej, Wrocław.

Jorgensen L.

1988 Family Burial Practices and Inheritance Systems. The Development of an Iron Age Society from 500 $B C$ to $A D 1000$ on Bornholm, Denmark, „Acta Archaeologica”, t. 58, s. 17-53.

Jung C. G.

1988 Fenomenologia archetypu dziecka, (w:) Dziecko, t. 2, Gdańsk, s. 255-269.

Kietlińska A.

1959 Problem tzW. grobów książęcych we wczesnym okresie rzymskim, „Wiadomości Archeologiczne”, t. XXVI, s. 98-118.

Kowalczyk E.

2004 Chrześcijańskie miłosierdzie. Rzecz o pochówkach dzieci nie ochrzczonych (na przykładzie północnego Mazowsza), (w:) Dusza maluczka a strata ogromna, Funeralia Lednickie (Spotkanie 6), red. W. Dzieduszycki, J. Wrzesiński, Poznań, s. 103-115.

Malinowski A.

1964 Szczątki czaszek ludzkich z grodziska i osady otwartej ludności kultury hużyckiej w Słupcy, „Fontes Archeologici Posnanienses", t. XV, s. 155-157.

Malinowski T.

1968 The Problem of Cannibalism among Tribes of the Lusatian Culture in Poland, „Archaeologia Polona", t. X, s. 147-153.

1985 Wielkopolska w otchłani wieków, Poznań.

Minta-Tworzowska D.

2000 Symbole i symbolika z perspektywy badań archeologicznych, (w:) Kultura symboliczna kręgu pól popielnicowych epoki brązu $i$ wczesnej epoki żelaza w Europie Środkowej, red. B. Gediga, D. Piotrowska, Warszawa-Wrocław-Biskupin, s. 45-54.

Muzolf B.

2002 Kompleks osadniczy z okresów halsztackiego i lateńskiego. Wyniki ratowniczych badań wykopaliskowych na terenie odkrywki „Szczerców” KWB „Bełchatów” S.A. na stanowisku nr 11 w Grabku, gm. Szczerców, woj. łódzkie, (w:) Badania, t. 2, red. J. Grygiel, Łódź, s. 121-385.

Müller J.

1994a Zur sozialen Gliederung der Nachbestattungensgemeinschaft vom Magdalenenberg bei Vilingen, „Praehistorische Zeitschrift”, t. 69, s. 175-221.

1994b Bestattungsformen als Spiegel dualer Organisation in prähistorischen Gesellschaften, „Mitteilungen der Berliner Gesellschaft für Anthropologie, Ethnologie und Urgeschichte”, t. 15, s. 81-88.

Ostoja-Zagórski J.

1996 Najstarsze dzieje ziem polskich, Bydgoszcz.

Pałubicka A., Tabaczyński S.

1986 Społeczeństwo i kultura jako przedmiot badań archeologicznych, (w:) Teoria i praktyka badań archeologicznych, t. 1: Przesłanki metodologiczne, red. W. Hensel, G. Donato, S. Tabaczyński, Wrocław, s. $57-183$. 
Piontek J

1983 Wstępna analiza biologiczna lokalnej społeczności z okresu halsztackiego, zamieszkującej mikroregion osadniczy w Wicinie, woj. zielonogórskie, (w:) Przemiany ludnościowe i kulturowe I tysiąclecia p.n.e. na ziemiach między Odrą a Dnieprem, red. W. Hensel, Wrocław, s. 459-463.

Prokopowicz J.

1961 Wyniki badań wykopaliskowych na stanowisku I w Janowicach, pow. Miechów, „Materiały Archeologiczne", t. III, s. 51- 63.

Przeworska J.

1971 Religie Celtów, Warszawa.

Pyzel J., Sobkowiak-Tabaka I.

2004 Problematyka dzieci w archeologii neolitu. Wybrane aspekty, (w:) Dusza maluczka a strata ogromna, Funeralia Lednickie (Spotkanie 6), red. W. Dzieduszycki, J. Wrzesiński, Poznań, s. 333-341.

Rożnowski F.

1989 Badania antropologiczne ludności kultury łużyckiej na Pomorzu, (w:) Problemy kultury hużyckiej na Pomorzu, red. T. Malinowski, Słupsk, s. 147-155.

1993 Antropologiczna analiza materiałów kostnych z cmentarzyska w Masłowie, gm. Wyrzysk, woj. pilskie, (w:) Miscellanea archaeologica Thaddaeo Malinowski dedicata, red. F. Różnowski, SłupskPoznań, s. 313-325.

Rysiewska T.

1996 Struktura rodowa w społecznościach pradziejowych. Cmentarzyska z epoki brązu $i$ wczesnej epoki żelaza w południowej Polsce, Wrocław.

Strzałko J., Olińska K.

1983 Przemiany biologiczno-ludnościowe populacji lokalnej z okresu halsztackiego, związanej z grodem w Sobiejuchach, (w:) Przemiany ludnościowe i kulturowe I tysiąclecia p.n.e. na ziemiach między Odrą a Dnieprem, red. W. Hensel, Wrocław, s. 453-459.

Szybowicz B.

1996 Analiza antropologiczna i demograficzna przepalonych szczątków kostnych z cmentarzyska grupy tarnobrzeskiej $w$ Chodaczowie, stanowisko 1, (w:) Problemy epoki brązu $i$ wczesnej epoki żelaza w Europie Środkowej. Księga jubileuszowa poświęcona Markowi Gedlowi, red. J. Chochorowski, Kraków, s. 481-489.

Topolski J.

1983 Teoria wiedzy historycznej, Poznań.

Urbański M.

2002 Cmentarzysko kultury pomorskiej, (w:) Badania, t. 2, red. R. Grygiel, Łódź, s. 385-401.

Wieczorowski T.

1938 Rzadsze wyroby gliniane, (w:) Gród prasłowiański w Biskupinie w powiecie żnińskim, red. J. Kostrzewski, Poznań, s. 33-39.

Wiślański T.

1969 Podstawy gospodarcze plemion neolitycznych w Polsce pólnocno-zachodniej, Wrocław-WarszawaKraków.

Wokroj F.

1958 Szczątki ludzkie z grodziska kultury łużyckiej w Shupcy, „Fontes Archaeologici Posnanienses”, t. VIII-IX, s. 137-143.

Woźny J.

2000 Symbolika przestrzeni miejsc grzebalnych w czasach ciałopalenia zwłok na ziemiach polskich (od środkowej epoki brązu do środkowego okresu lateńskiego), Bydgoszcz. 
Żychlińska J., Rogalski B.

2006 Wyniki ratowniczych badań archeologicznych na stanowisku 2 w miejscowości Łęczyska, pow. Pajęczno, woj. łódzkie, (w:) Badania, t. 5, red. R. Mazurowski, W. Dzieduszycki, D. Żychliński, Poznań, s. 13-180.

\section{SOME REMARKS ON THE MARGIN OF STUDIES ON SOCIAL RELATIONS OF 'LUSATIAN' CULTURE COMMUNITIES}

\section{S u m m ary}

It has been argued that the Bronze Age marks a significant threshold in social relations, in particular in treatment of children. As in the preceding period a large number of children has not been granted a right of being buried at kin cemeteries, this practice has been significantly altered in the Bronze Age resulting in only a small portion of children buried elsewhere. This is arguably due to decreasing self-inclusiveness of human groups of Lusatian culture in Central Europe, caused by breaking up neighbouring isolation as a consequence of the emergence of stable contacts between different groups. This new situation was caused by a need of procuring raw material and acquiring bronze objects, which must have influenced social relations of the time and resulted in treating strangers not longer as enemies but partners. This is turn have led to granting the kin status to newborns and treating rites of passage exclusively in a symbolic way. Consequently, rules of social inclusiveness, in relation to both individuals related to a kin group and the other, became less strict and pronounced. At the same time, it is noticed that a number of children buried at different cemeteries is significantly lower than expected. It may indicate that not all deceased children have been buried at the main cemetery, which may be further supported by new empirical materials.

Children burials are often found at Neolithic settlements but they remain very rare at settlements of the Lusatian culture (e.g. Janowice, Lesser Poland province, Wieruszów, Łódź province, Grodno, Kujavia-Pomerania province, Gzin, Kujavia-Pomerania province, Zabrzezie, Łódź province). Of particular significance is the settlement at Łęczyska, Łódź province, where cluster of burials has been found next to typical dwelling features and empty spaces around them, implying a deliberate selection of burial ground. This is certainly the case in which some children and adults are not allowed to be buried at the kin cemetery. Reasons for this exclusion of children could be numerous including e.g. individuals belonging to this community but otherwise remaining outside it due to impossible to grasp causes or children originating from an alien group and otherwise not granted a relevant social status. The other possibilities include mentally and physically handicapped children, prematurely born, or children not recognized by the father, or less often mother, and consequently excluded from the family. A premature or unnatural death always proved anxiety as it was against the very logic of human existence and philosophy of life. It interfered with the order of things, coupled with a failing of human fate, and therefore was something unnatural, which poses a threat to the return of the dead among the living. If we assume that the death was a transition from one state to the other, this transition required the closure of the existing burial rite, which closed the presence of the deceased among the living and eased its transition to the world of the dead, while preventing his return. The failure of arranging such rites (for various reasons), resulted in leaving the deceased in the intermediate state and somehow suspending it at 
the border of the living and the dead. It seems that such rituals were in fact performed, as implied by the settlement at Łęczyska, where burials are placed in three distinct clusters, which corresponds to the triple scheme of rites de passages. Moreover, two groove like features have also been discovered at the settlement. One of them was of a semilunar shape while the other was inverted U-shaped. Their 'entrances' have been directed towards these clusters of burials (see also similar cult features at the cemetery in Kietrz, Opole province).

We are dealing here with preventing some of the dead from being buried at the kin cemetery, which does mean that they were denied the right to burial. Moreover, the expression of their place of burial is distinctively prominent, as manifested by their close relation to the sphere of the sacred, itself referring to the socially sanctioned 'cemetery' rules

Translated by Arkadiusz Marciniak

Justyna Żychlińska

Katedra Archeologii, Uniwersytet Kazimierza Wielkiego ul. Przemysłowa 34, 85-758 Bydgoszcz, Poland 